\title{
Lebestatin, a disintegrin from Macrovipera venom, inhibits integrin-mediated cell adhesion, migration and angiogenesis
}

\author{
Kallech-Ziri Olfa ${ }^{1}$, Luis Josée ${ }^{2, *}$, Daoud Salma ${ }^{1, *}$, Bazaa Amine ${ }^{1}$, Srairi Abid Najet ${ }^{1}$, \\ Andreotti Nicolas ${ }^{3}$, Lehmann Maxime ${ }^{2}$, Zouari Raoudha ${ }^{1}$, Mabrouk Kamel ${ }^{3}$, \\ Marvaldi Jacques ${ }^{2}$, Sabatier Jean-Marc ${ }^{3}$, El Ayeb Mohamed ${ }^{1}$ and \\ Marrakchi Naziha ${ }^{1,4}$
}

${ }^{1}$ Laboratoire des Venins et Toxines, Institut Pasteur de Tunis, Tunis Belvédère, Tunisie; ${ }^{2}$ CNRS FRE2737, Faculté de Pharmacie, Marseille, France ${ }^{3}$ CNRS UMR 6560, Boulevard Pierre Dramard, Marseille Cedex, France and ${ }^{4}$ Faculté de Médecine de Tunis, Tunis, Tunisie

\begin{abstract}
Lebestatin, a new member of the lysine-threonine-serine (KTS)-disintegrin family, was purified to homogeneity from Tunisian snake (Macrovipera lebetina) venom. It is a single-chain polypeptide composed of 41 amino acids. The amino-acid sequence of lebestatin shows that it displays a pattern of cysteines similar to other short disintegrins, but contains the sequence KTS rather than RGD in its integrin-binding loop. Lebestatin presents a high homology with obtustatin and viperistatin. Lebestatin interacts specifically with the $\alpha 1 \beta 1$ integrin. It was thus able to inhibit both adhesion and migration of PC12 and $\alpha 1 \beta 1$ integrin-expressing $\mathrm{CHO}$ cells (CHO- $\alpha 1)$ to type I and IV collagens. This disintegrin also affected adhesion and migration of endothelial cells and exhibited an anti-angiogenic effect in vivo when using the 8-day-old embryo chick chorioallantoic membrane model.
\end{abstract} Laboratory Investigation (2005) 85, 1507-1516. doi:10.1038/labinvest.3700350; published online 3 October 2005

Keywords: venom; disintegrin; KTS motif; CAM model; $\alpha 1 \beta 1$ collagen receptor

Disintegrins are a family of low molecular weight proteins present in many viperidae venoms. ${ }^{1,2}$ They are divided into five different subgroups according to their polypeptide length and number of disulfide bonds. The long subgroup (83 amino acids) with seven disulfide bonds, includes bitistatin. The medium subgroup (68-73 amino acids) with six disulfide bonds contains, kistrin, flavoridin and barbourin. The third subgroup includes the short disintegrins, single polypeptide chains of 49-51 amino acids with four disulfide bonds, echistatin and eristostatin belong to this group. The disintegrin domains of PIII snake-venom metalloproteinases containing approx. Hundred amino acids with 16 cysteine residues involved in the formation of eight disulfide bonds constitute the fourth subgroup of the disintegrin family. Unlike short-, medium- and long-sized disintegrins, which are single-chain

Correspondence: Dr M Naziha, PhD, Institut Pasteur de Tunis, 13, Place Pasteur-BP.74, Tunis-Belvedere 1002, Tunisie.

E-mail: marrakchi_naziha@yahoo.fr

*These authors contributed equally to this work

Received 5 April 2005; revised 12 July 2005; accepted 14 July 2005; published online 3 October 2005 molecules, the fifth subgroup is composed of homoand heterodimers. ${ }^{3}$

Snake disintegrins are potent and specific antagonists of several integrins, which are a superfamily of structurally related $\alpha \beta$ heterodimers. Integrins represent a major class of adhesion receptors. ${ }^{4,5}$ They participate in the complex biological process of embryonic development and in the maintenance of tissue integrity. They also function in wound healing and pathological processes such as inflammation and malignant transformation by affecting cellular activities like cell growth, differentiation, migration and apoptosis. ${ }^{4,6}$ For example, the integrin $\alpha 1 \beta 1$, a receptor of laminin-1 and collagens, has been involved in cell migration and tumor angiogenesis. ${ }^{7}$ Snake disintegrins were demonstrated to have a potent antiangiogenic activity. ${ }^{8-11}$

The integrin-inhibitory activity of disintegrins depends on the appropriate pairing of cysteine residues, which determines the conformation of the inhibitory loop. ${ }^{2}$ Most disintegrins contain an Arg-Gly-Asp (RGD) sequence in the carboxyl-terminal half of the molecule, which is essential to their ability to block integrin interaction with ligands. ${ }^{1,12}$ Barbourin, the most selective inhibitor of $\alpha \operatorname{IIb} \beta 3$ integrin, was the first described disintegrin with an 
active KGD sequence ${ }^{13}$ instead of RGD. Subsequently, many such venom proteins have been identified, including atrolysin $\mathrm{E}$ which has an MVD motif in its inhibitory loop. ${ }^{14}$ CC8, a heterodimeric disintegrin isolated from the venom of Cerastes cerastes, contains a WGD sequence and is a potent and selective inhibitor of $\alpha \operatorname{IIb} \beta 3, \alpha v \beta 3$ and $\alpha 5 \beta 1$ integrins. ${ }^{15}$ Two new disintegrins, obtustatin and viperistatin, were recently isolated from the venom of the Vipera lebetina obtusa and Vipera palestinae, respectively. ${ }^{16,17}$ They have only 41 amino acids and are considered the shortest disintegrins yet described. They contain a lysine-threonineserine (KTS) motif in the integrin recognition loop and are selective inhibitors of the binding of integrin $\alpha 1 \beta 1$ to type IV and type I collagens. ${ }^{11,17}$

Here we report the amino-acid sequence and biological characterization of a novel short disintegrin, lebestatin, isolated from the venom of Macrovipera lebetina. This disintegrin has a very high homology with obtustatin, and viperistatin and exhibits highly inhibitory effects on cell adhesion and cell migration to collagens I and IV. Also, it shows in vivo anti-angiogenic activity.

\section{Materials and methods}

\section{Materials}

Venom was collected from Macrovipera lebetina snakes in the Pasteur Institute's Serpentarium (Tunis, Tunisia) and stored at $-20^{\circ} \mathrm{C}$. Dulbecco's modified Eagle's medium (DMEM) and RPMI 1640 medium were purchased from GIBCO (Cergy-Pontoise, France) and horse and fetal calf serum (FCS) from Bio Whittaker (Fontenay-sous-Bois, France). Platelet-derived growth factor (PDGF), vascular endothelial growth factor (VEGF), human fibrinogen, human laminin-1 and rat type IV collagen were from Sigma (St- Louis, MO, USA). Rat type I collagen was from Upstate (Lake Placid, NY, USA) and human fibronectin from Chemicon (Temecula, CA, USA). Human vitronectin was purified according to Yatogho et $a l^{18}$ Zeocin $^{\mathrm{TM}}$ was provided by Invitrogen (Cergy-Pontoise, France). The 3A3 antirat $\alpha 1$ subunit antibody was kindly provided by $S$ Carbonetto, McGill University, Montréal, while the FB12 anti-human $\alpha 1$ subunit antibody was from Chemicon. Anti- $\alpha 2$ (Gi9), anti- $\alpha 3$ (C3VLA3), anti- $\alpha \mathrm{v}$ antibody (69.6.5) and anti- $\beta 1$ (Lia1/2) were from Immunotech (Marseille).

\section{Purification of Lebestatin}

Crude venom (267 mg) of Macrovipera lebetina was dissolved in $0.2 \mathrm{M}$ ammonium acetate, $\mathrm{pH} 6.8$ and fractionated by a Sephadex G-75 (Pharmacia, Uppsala, Sweden) column equilibrated with the same buffer, as previously described. ${ }^{19,20}$ Fraction IV, containing the anti-platelet aggregation activity with low molecular mass, was collected and lyophilized for further purification. It was applied to a reverse phase C8 column $(250 \times 4.6 \mathrm{~mm}, 5 \mu \mathrm{m}$; Beckman; Fullerton, CA, USA) equilibrated with $0.1 \%$ trifluoroacetic acid (TFA) in $10 \%$ acetonitrile and then eluted at a flow rate of $0.8 \mathrm{ml} / \mathrm{min}$ with an acetonitrile linear gradient $10-63 \%$ over $45 \mathrm{~min}$. The homogeneity of lebestatin was assessed by a second step of high-performance liquid chromatography (HPLC) on a C18 column $(250 \times 4.6 \mathrm{~mm}, 5 \mu \mathrm{m}$; Beckman) under the conditions described above.

The apparent mass of the purified lebestatin was determined by SDS-PAGE method using $20 \%$ polyacrylamide without or with reduction by $2 \%$ $\beta$-mercaptoethanol. Molecular weight standards consisted of $\alpha_{2}$-Macroglobulin from human plasma $(180 \mathrm{kDa}), \quad \beta$-galactosidase from Escherichea coli $(116 \mathrm{kDa})$, phosphorylase $\mathrm{b}$ from rabbit muscle $(97.4 \mathrm{kDa})$, serum albumin from bovine $(66 \mathrm{kDa})$, fumarase from porcine heart $(48.5 \mathrm{kDa})$, carbonic anhydrase from bovine erythrocytes $(29 \mathrm{kDa}), \beta$ lactoglobulin from bovine milk $(18.4 \mathrm{kDa}), \alpha$-lactalbumin from bovine milk $(14.2 \mathrm{kDa})$ and aprotinin from bovine lung $(6.5 \mathrm{kDa})$. Proteins were stained with Coomassie blue.

\section{Structural Characterization of Lebestatin and Peptide Quantification}

Purified lebestatin was reduced by incubation for $1 \mathrm{~h}$ at $37^{\circ} \mathrm{C}$ in $6 \mathrm{M}$ guanidine- $\mathrm{HCl} ; 0.5 \mathrm{M}$ Tris/HCl; $2 \mathrm{mM}$ ethylene-diamine tetra-acetic acid; $1.4 \mu \mathrm{M}$ dithiothreitol (DTT), $\mathrm{pH}$ 7.5. Lebestatin was then alkylated at final concentration of $9 \mu \mathrm{M}$ 4-vinylpyridine. The reaction was stopped after $5 \mathrm{~min}$ by addition of $14 \mu \mathrm{mol}$ of DTT. The mixture was desalted by reverse-phase HPLC on a C18 column as described above for protein purification.

The amino-acid sequence of S-alkylated protein was determined by Edman degradation in an Applied Biosystem 476 A protein sequencer. Sequence homology was evaluated by a computer search in the protein sequence database using BLAST program implemented in the Protein-protein BLAST (blastp) search at http://www.ncbi.nlm.nih. gov.

Determination of the molecular mass of native lebestatin was carried out on a Voyager DE-RP MALDI-TOF mass spectrometer (Biosystem, Framingham, MA, USA). Lebestatin was dissolved in $\mathrm{CH}_{3} \mathrm{CN} / \mathrm{H}_{2} \mathrm{O}$ (30:70) with $0.3 \%$ TFA. The matrix solution was prepared as follows: alpha-cyano 4hydroxycinnamic acid was dissolved in $50 \% \mathrm{CH}_{3} \mathrm{CN}$ in $0.3 \% \mathrm{TFA} / \mathrm{H}_{2} \mathrm{O}$ to obtain a saturated solution at $10 \mu \mathrm{g} / \mu \mathrm{l}$. Equal volumes $(0.5 \mu \mathrm{l})$ of peptide solution and matrix solution were combined and allowed to dry. Mass spectra recorded in linear mode were externally calibrated with suitable standards and then analyzed by the GRAMS/386 software.

Peptide quantification was accomplished after determination of the molecular mass and aminoacid sequence. The extinction coefficient for lebes- 
tatin was calculated according to Gill et $a 2^{21}$ using the following formula:

$$
\sum_{280}=5690 n_{\mathrm{trp}}+1280 n_{\mathrm{tyr}}+120 n_{\mathrm{ss}}
$$

where $n_{\text {trp }}, n_{\text {tyr }}$ and $n_{\mathrm{ss}}$ represent the number of tryptophane residues, tyrosine residues and disulfide bonds, respectively). Absorbance at $280 \mathrm{~nm}$ was determined using a Beckman DU 640 spectrophotometer. Concentration of lebestatin was determined according to the Beer-Lambert law.

\section{Cells}

Human colonic adenocarcinoma (HT29-D4) and fibrosarcoma (HT1080) cells were routinely cultured in DMEM containing 10\% FCS. Human leukemia (K562) and ovarian adenocarcinoma (IGROV1) cells were cultured in RPMI 1640 medium containing 10\% FCS. Rat pheochromocytoma (PC12) cells were cultured in DMEM supplemented with 5\% FCS and $10 \%$ heat-inactivated horse serum. Human microvascular endothelial cells (HMEC-1) were cultured as described. ${ }^{22}$

The cDNA sequence encoding rat $\alpha 1$ integrin subunit was excised from pBS plasmid by EcoR1 digestion and subcloned into the EcoR1 site of pZeoSVS plasmid (Invitrogen). Chinese hamster ovary (CHO-K1) cells were transfected with Lipofectamin (Invitrogen) according to the supplier instructions. Stable cells were selected and maintained in DMEM supplemented with $10 \%$ FCS and $500 \mu \mathrm{g} / \mathrm{ml}$ Zeo$\operatorname{cin}^{\text {TM }}$. Clonal populations were obtained by limited dilution. a1-expressing clones were selected by FACS analysis using $3 \mathrm{~A} 3$ function blocking mAb.

\section{Cell Adhesion and Migration Assays}

Adhesion assays were performed as previously described. ${ }^{23,24}$ Briefly, cells in single cell suspension were added to wells coated with purified extracellular matrix (ECM) proteins and allowed to adhere to the substrata for $1 \mathrm{~h}$ (HMEC-1, HT1080, IGROV1, CHO- $\alpha 1$ and PC12 cells) or $2 \mathrm{~h}$ (HT29-D4 and $\mathrm{K} 562$ cells) at $37^{\circ} \mathrm{C}$. After washing, attached cells were fixed, stained by $0.1 \%$ crystal violet and lysed with 1\% SDS. Absorbance was then measured at $600 \mathrm{~nm}$.

In vitro cell migration assays were performed in modified Boyden chambers (NeuroProbe Inc., Bethesda, MD, USA) with porous membranes precoated with $10 \mu \mathrm{g} / \mathrm{ml}$ of type IV collagen as previously described, ${ }^{23,24}$ except that cells were stained with $0.1 \%$ crystal violet. Cell migration was then quantified by measurement the absorbance at $600 \mathrm{~nm}$.

\section{Chick Chorioallantoic Membrane (CAM) Angiogenesis Assay}

Chick embryos from 3-day-old eggs were opened and put in double Petri dishes with water for humidity. After 5 days at $37^{\circ} \mathrm{C}$, filter paper discs
( $\varnothing 6 \mathrm{~mm})$ soaked in buffer $(0.9 \% \mathrm{NaCl})$ or lebestatin $(0.1 \mu \mathrm{g} / \mathrm{embryo})$ were applied on the CAM. Spontaneous angiogenesis was observed and photographed every day. To check the effect of lebestatin on growth factor-induced angiogenesis, PDGF (10 ng/embryo) or VEGF (200 ng/embryo)-impregnated filter discs were administrated topically on the CAM of 8-dayold embryos. After $24 \mathrm{~h}$, lebestatin $(0.5 \mu \mathrm{g})$ was applied to the CAM and blood vessels were photographed with a digital camera at $\times 10$ magnification after $72 \mathrm{~h}$ of incubation. Quantification of angiogenesis was carried out in digitized images by measuring the total blood vessels length using Metaview software. Measures were performed by three experimenters in a circle, centered on filter disc, that represents $50 \%$ of the total CAM surface.

\section{Molecular Modeling}

Molecular modeling of lebestatin and viperistatin was achieved using MODELLER, ${ }^{25}$ based on the obtustatin structure (PDB code 1MPZ) as template. Using the lowest MODELLER objective energy, we selected the 10 best models that were averaged by NMRCLUST 1.2 into a single model. PROCHECK V3.5.4 was used to confirm that the geometric quality of all models generated by molecular modeling was correct. ${ }^{26}$

\section{Results}

\section{Purification of Lebestatin}

The crude venom of Macrovipera lebetina was separated into five fractions by gel filtration on a Sephadex G-75 column as described. ${ }^{19,20}$ The fraction IV was the lowest concentration and exhibited antiplatelet aggregation activity and contained peptides with low molecular weight. ${ }^{27}$ This fraction was collected, lyophilized and applied to a reversephase HPLC C8 column. Five peaks were detected (Figure 1a). The peaks $\mathrm{IV}_{1}$ and $\mathrm{IV}_{4}$ have been previously characterized and termed lebetins 1 and 2 , respectively. ${ }^{27,28}$ Characterization of peaks $\mathrm{IV}_{3}$ and $\mathrm{IV}_{5}$ will be reported elsewhere. Here, we describe the purification of the second peak $\left(\mathrm{IV}_{2}\right)$ by reversephase HPLC using a C18 column. One sharp peak was detected and designated as lebestatin (Figure 1b). Moreover, purified lebestatin was analyzed by SDS-PAGE under nonreducing and reducing conditions. The analysis revealed a monomeric band at about $4 \mathrm{kDa}$ (insert Figure 1b). The purity was also checked by MALDI-TOF mass spectrometry (data not shown).

\section{Structural Characterization of Lebestatin}

The entire amino-acid sequence of lebestatin was established using automated Edman degradation. The protein consists of 41 amino acids including eight cysteines (Figure 2). The calculated isotopeaveraged molecular mass of lebestatin assuming all 
cysteines as $\mathrm{S}-\mathrm{S}$ bonds is $4406.8 \mathrm{Da}$ and is in agreement with that determined experimentally by MALDI-TOF mass spectrometry (4411.52 Da) (data not shown).

The sequence analysis showed that lebestatin has a high sequence homology with known venom disintegrins. The alignment of amino-acid sequence of lebestatin with those of obtustatin (Vipera lebetina obtusa), ${ }^{16}$ viperistatin (Vipera palestinae), ${ }^{17}$ echistatin (Echis carinatus), ${ }^{29}$ kistrin (Agkistrodon rhodostoma) ${ }^{30}$ and flavoridin (Trimeresurus flavoridis $^{31}$ is shown in Figure 2. The highest sequence
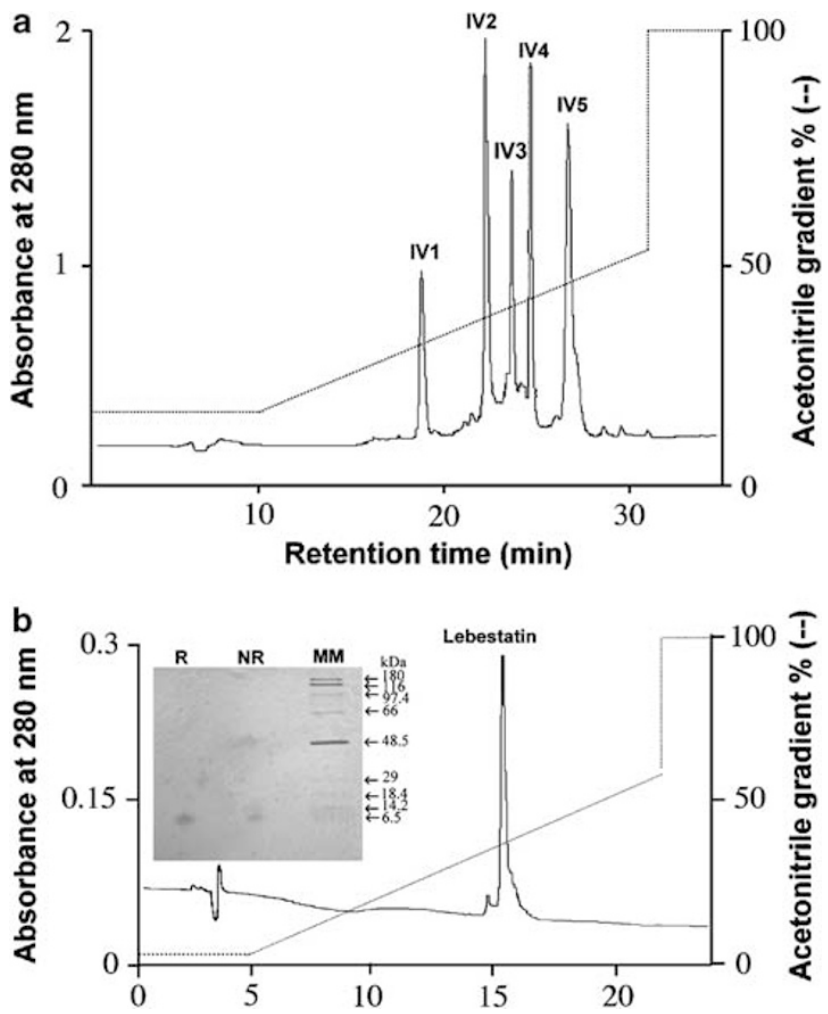

Figure 1 Purification of lebestatin. (a) Fraction IV, exhibiting antiplatelet aggregation activity and possessing peptides with low molecular weight, was applied to an RP-HPLC C8 column. (b) Fraction $\mathrm{IV}_{2}$, lebestatin, was further analyzed by a C18 column. SDS-PAGE $(20 \%)$ was performed under nonreducing (NR) and reducing $(\mathrm{R})$ conditions and stained with Coomassie blue. identity was observed with KTS motif-containing short disintegrins. Indeed, lebestatin differs from viperistatin and obtustatin in only two amino acids flanking the KTS loop and/or in the C-terminal part.

\section{Lebestatin is a Selective Inhibitor of $\alpha 1 \beta 1$ Integrin}

Snake venom disintegrins are potent and specific antagonists of various integrins. The amino-acid sequence similarities of lebestatin with obtustatin and viperistatin suggest that our disintegrin might block the $\alpha 1 \beta 1$ integrin. We therefore performed adhesion assays on type I and IV collagens, two ligands of $\alpha 1 \beta 1$, by using CHO cells transfected with the rat $\alpha 1$ integrin subunit. As illustrated in Figure 3, lebestatin abolished the attachment of CHO- $\alpha 1$ cells to type I collagen, while inhibition was almost complete on type IV collagen. To make sure of the specificity for $\alpha 1 \beta 1$, we next checked the lebestatin effect on various cell/ECM protein pairs involving unique integrins: $\alpha 2 \beta 1$ (HT1080/type I collagen), $\alpha 5 \beta 1$ (K562/fibronectin), $\alpha \mathrm{v} \beta 3$ (IGROV1/fibrinogen), $\alpha \mathrm{v} \beta 5$ (HT29-D4/vitronectin), $\alpha \mathrm{v} \beta 6$ (HT29-D4/fibronectin) and $\alpha 6 \beta 4$ (HT29-D4/laminin-1). The adhesive function of these integrins was not affected by lebestatin (Figure 3).

As shown in Figure 4a, the $\alpha 1 \beta 1$ integrin is the receptor for type I and IV collagens in rat pheochromocytoma cells PC12. Indeed, the monoclonal antibody 3A3 against rat $\alpha 1$ subunit readily inhibited attachment of both CHO- $\alpha 1$ and PC12 cells on collagens. We therefore used PC12 cells to determine the efficiency of lebestatin to inhibit cell adhesion. The effect on PC12 cell attachment to type I collagen was dose dependent (Figure 4b). The concentration of lebestatin giving half-maximal inhibition of cell adhesion on type I collagen was $0.2 \mathrm{nM}$ for PC12 cells (Figure 4b) and $0.4 \mathrm{nM}$ for CHO- $\alpha 1$ cells (not shown). Similar results were obtained on type IV collagen (data not shown).

\section{Lebestatin Inhibits Cell Migration}

We tested the ability of lebestatin to inhibit integrindependent migration of CHO- $\alpha 1$ and PC12 cells,

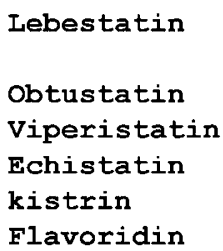

Figure 2 Determination of the amino-acid sequence of lebestatin. Comparison of the amino-acid sequence of lebestatin with those of others snake venom disintegrins. Sequence homology was evaluated by computer search in the protein sequence database (BLAST (blastp) search). Alignment of the amino-acid sequence of disintegrins was performed with the program CLUSTALW. '*' means that the residues in that column are identical in all sequences in the alignment. '?' means that conserved substitutions have been observed. '.' means that semiconserved substitutions are observed. The underlined are amino-acid residues that are different in lebestatin, viperistatin and obtustatin. 


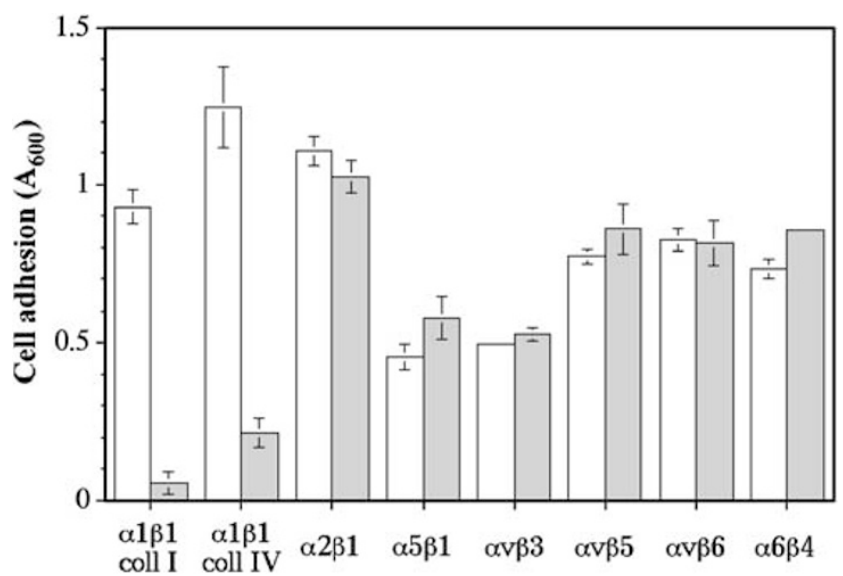

Figure 3 Effect of lebestatin on various integrins in cell adhesion assays. Adhesion assays were performed with various cell/ECM protein pairs involving unique integrins: $\alpha 1 \beta 1$ (PC12/type I or IV collagens) $\alpha 2 \beta 1$ (HT1080/type I collagen), $\alpha 5 \beta 1$ (K562/fibronectin), $\alpha \mathrm{v} \beta 3$ (IGROV1/fibrinogen), $\alpha \mathrm{v} \beta 5$ (HT29-D4/vitronectin), $\alpha \mathrm{v} \beta 6$ (HT29-D4/fibronectin) and $\alpha 6 \beta 4$ (HT29-D4/laminin-1). Cells were preincubated without (open bar) or with $100 \mathrm{nM}$ lebestatin (shade bar) for $30 \mathrm{~min}$ at room temperature. Cells were then added to 96well microtiter plates coated with $5 \mu \mathrm{g} / \mathrm{ml}$ fibronectin, vitronectin or laminin-1, with $10 \mu \mathrm{g} / \mathrm{ml}$ type I or IV collagens or with $50 \mu \mathrm{g} / \mathrm{ml}$ fibrinogen and allowed to adhere for 1 or $2 \mathrm{~h}$ at $37^{\circ} \mathrm{C}$. After washing, adherent cells were stained with crystal violet, solubilized by SDS and absorbance was measured at $600 \mathrm{~nm}$. Data shown ( \pm s.d.) are from one experiment representative of two or three performed in triplicate.

using haptotaxis assays towards attractive proteins in modified Boyden chambers. Lebestatin impaired migration of CHO- $\alpha 1$ cells towards type IV (Figure 5a) and type I (not shown) collagens. This inhibition was dose-dependent, with an half-maximal inhibition at a concentration as low as $0.1 \mathrm{nM}$ (Figure 5b) and an almost maximal effect at $1 \mathrm{nM}$. Migration of CHO- $\alpha 1$ cells towards type IV collagen is likely $\alpha 1 \beta 1$ integrin-dependent as 3A3 antibody completely blocked migration (Figure 5b). Lebestatin also impaired migration of PC12 cell line to type IV collagen (data not shown).

\section{Effect of Lebestatin on Angiogenesis}

Recent studies showed a critical role for $\alpha 1 \beta 1$ integrin in angiogenesis. ${ }^{7}$ Moreover, the closely related disintegrin obtustatin, inhibited angiogenesis in chicken CAM assays. ${ }^{11}$ We therefore checked, for the first time, whether lebestatin could inhibit endothelial cell integrins. As illustrated in Figure 6a, lebestatin partially inhibited adhesion of human microvascular endothelial cells (HMEC-1) to type IV collagen. The extent of the effect ( $46 \%$ inhibition) was very similar to that observed with a functionblocking antibody against human $\alpha 1 \beta 1$ integrin ( $48 \%$ inhibition), suggesting that HMEC-1 adhesion to type IV collagen involves additional integrins. Similar results were obtained with type I collagen and laminin-1, two other $\alpha 1 \beta 1$ integrin ligands (not
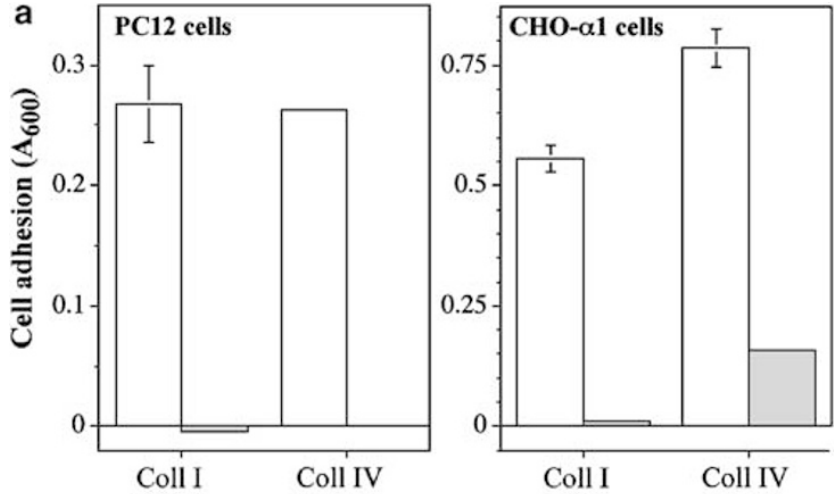

b

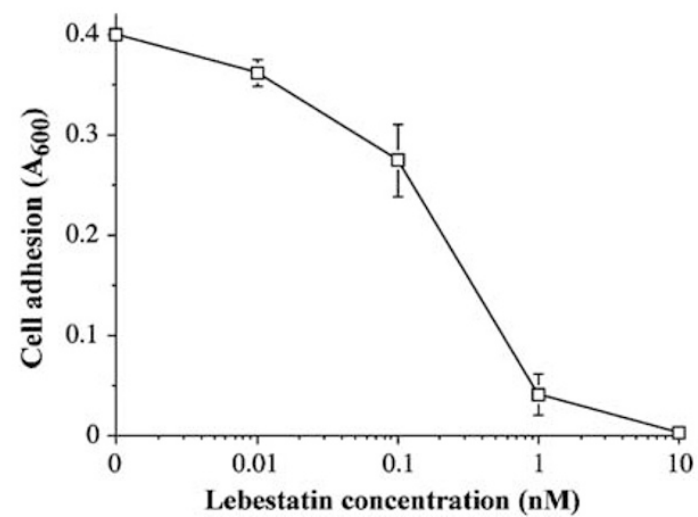

Figure 4 Dose-effect of lebestatin on $\alpha 1 \beta 1$-dependent cell adhesion. (a) CHO- $\alpha 1$ and PC12 cells were preincubated with $10 \mu \mathrm{g} / \mathrm{ml}$ anti- $\alpha 1$ integrin antibody for $30 \mathrm{~min}$ at room temperature. Cells were then added to 96 -well microtiter plates coated with $10 \mu \mathrm{g} / \mathrm{ml}$ type I or IV collagens and allowed to adhere for $1 \mathrm{~h}$ at $37^{\circ} \mathrm{C}$. After washing, adherent cells were stained with crystal violet, solubilized by SDS and absorbance was measured at $600 \mathrm{~nm}$. (b) PC12 cells were preincubated with the indicated concentrations of lebestatin for $30 \mathrm{~min}$ at room temperature. Cell adhesion on type I collagen was measured as above. Data shown are means ( \pm s.d.) from three experiments performed in triplicate.

shown). Combination of anti-integrin subunits antibodies show that residual lebestatin-resistant adhesion was due to $\alpha 2 \beta 1$ and other $\beta 1$-containing integrins (Figure 6a). Similar results were obtained regarding cell migration in modified Boyden chambers. Thus, HMEC-1 migration to type IV collagen was only partially inhibited both by lebestatin and anti- $\alpha 1$ antibody (Figure 6b).

The effect of lebestatin on in vivo angiogenesis was evaluated by using the chick CAM assay (Figure 7). Upon dissection of the CAM of 8-day-old chick embryos, the spontaneous angiogenesis in CAM was clearly observed after $72 \mathrm{~h}$ (Figure 7a). As illustrated in Figure $7 \mathrm{~b}$ and c, topical application of lebestatin inhibited the spontaneous angiogenesis in a dosedependent manner. The new vessel formation was considerably reduced with $0.1 \mu \mathrm{g}$ of lebestatin per embryo (Figure 7b).

Furthermore, chick CAM assays were performed under the induction of angiogenesis by PDGF (10 ng/ embryo) or VEGF (200 ng/embryo) for $48 \mathrm{~h}$ with or without the addition of lebestatin. Either PDGF or 


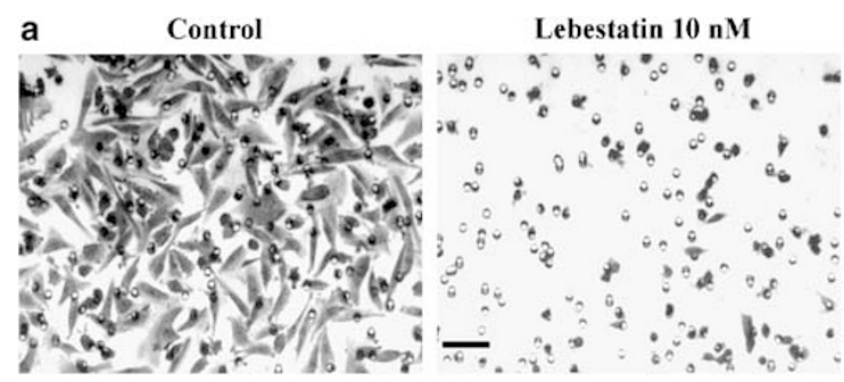

b

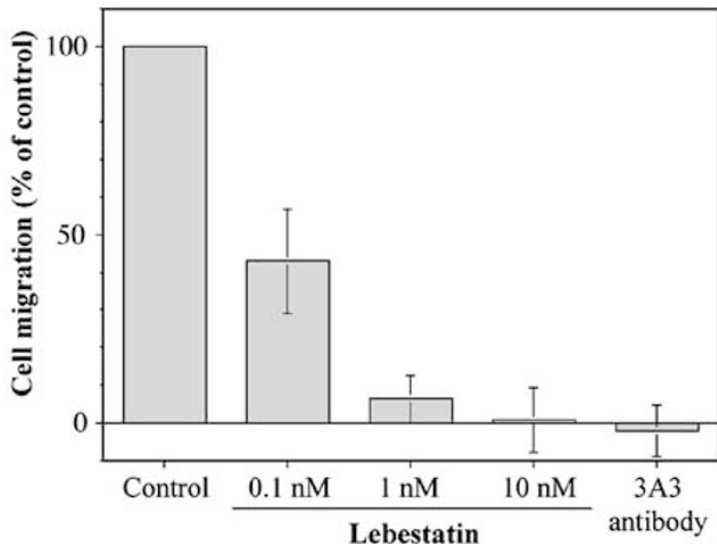

Figure 5 Lebestatin inhibits cell migration. (a) Cell motility was determined in a modified Boyden chamber using porous membrane precoated with $10 \mu \mathrm{g} / \mathrm{ml}$ of type IV collagen. After treatment with $10 \mathrm{nM}$ lebestatin for $30 \mathrm{~min}$ at room temperature, CHO- $\alpha 1$ cells were seeded into the upper reservoir and allowed to migrate through the filter towards the lower reservoir for $5 \mathrm{~h}$ at $37^{\circ} \mathrm{C}$. Cells that migrated to the underside of the filter were stained with $0.1 \%$ crystal violet. Scale bar: $100 \mu \mathrm{m}$. (b) Cell migration towards collagen was performed upon treatment with lebestatin at the indicated concentration or 3A3 antibody against $\alpha 1$ integrin subunit. After staining of cells with crystal violet, the colorant was solubilized with $1 \%$ SDS and absorbance was measured at $600 \mathrm{~nm}$. Data shown $( \pm$ s.d.) are from one experiment representative of three performed in triplicate. They are expressed as a percentage of adhesion in the absence of lebestatin.

VEGF induced a pronounced angiogenic response in this model (Figures $7 \mathrm{~d}$ and $\mathrm{f}$, respectively). Lebestatin as little as $0.5 \mu \mathrm{g}$ per embryo displayed a significant inhibition on PDGF- and VEGF-induced angiogenesis. Figures $7 \mathrm{e}$ and g show that lebestatin treatment after PDGF and VEGF, respectively, abruptly stopped capillary development. Vessels that developed prior to lebestatin treatment were not altered, indicating that lebestatin only blocks neoangiogenesis. Quantification of angiogenesis clearly shows that lebestatin treatment significantly reduced angiogenesis in both nonstimulated and angiogenic factor-stimulated conditions (Figure 7h).

\section{Discussion}

Disintegrins have numerous applications in studies on platelet thrombosis, endothelial cell apoptosis, migration and angiogenesis. ${ }^{32,33}$ Here, we report the purification of a novel short disintegrin (41 amino

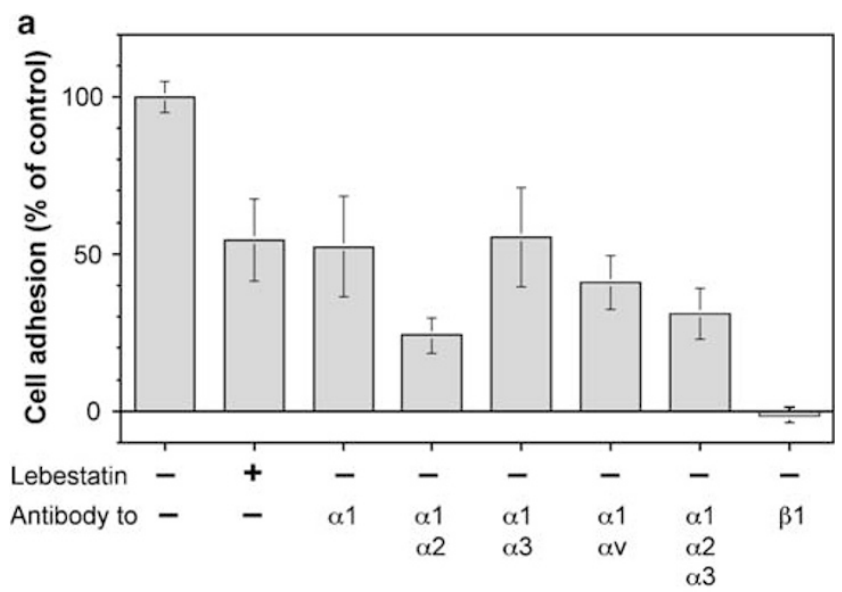

b

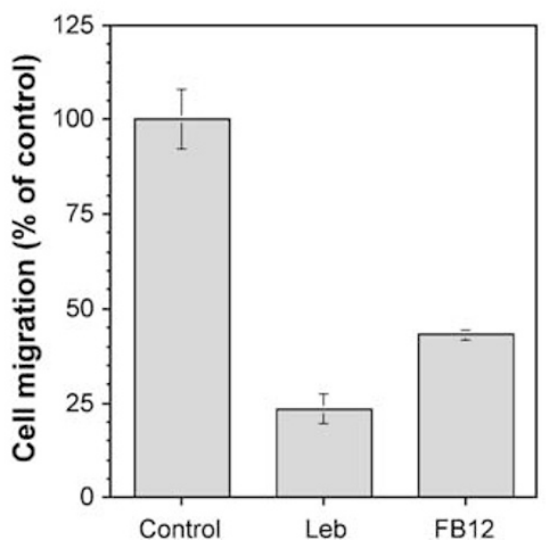

Figure 6 Effect of lebestatin on endothelial cell integrins. (a) Cell adhesion was performed as described in Figure 4a using HMEC-1 cells preincubated with $1 \mu \mathrm{M}$ lebestatin or with $10 \mu \mathrm{g} / \mathrm{ml}$ of antiintegrin antibodies. (b) Haptotaxis experiments and their quantification were performed as described in Figure 5a using HMEC-1 cells treated or not with $1 \mu \mathrm{M}$ lebestatin (Leb) or with $10 \mu \mathrm{g} / \mathrm{ml}$ of anti- $\alpha 1 \beta 1$ integrin antibody (FB12). Data shown $( \pm$ s.d.) are from one experiment representative of three performed in triplicate.

acids), lebestatin, isolated from Macrovipera lebetina venom. Lebestatin presents a high sequence homology with other snake venom disintegrins, in particular with short disintegrins such as obtustatin isolated from the venom of Vipera lebetina obtusa and viperistatin from the venom of Vipera palestinae (about 97\% identity). ${ }^{16,17}$ This high degree of similarity could be explained by the fact that these three vipers are different subspecies.

Integrins are essential mediators and regulators of physiological and pathological tumorigenesis and angiogenesis. The receptor $\alpha \mathrm{v} \beta 3$ has been identified as the first integrin target to inhibit tumor angiogenesis. ${ }^{32}$ However, recent findings suggest that additional integrins may also be valuable targets, in particular $\alpha 1 \beta 1, \alpha 2 \beta 1$ and $\alpha 5 \beta 1{ }^{34}$ Thus, combined addition of anti- $\alpha 1 \beta 1$ and anti- $\alpha 2 \beta 1$ antibodies reduced tumor growth and angiogenesis in mice. ${ }^{7}$ Many endogenous antiangiogenic molecules have also been identified such as arresten, which interacts with the $\alpha 1 \beta 1$ integrin. ${ }^{35}$ This integrin is also a 

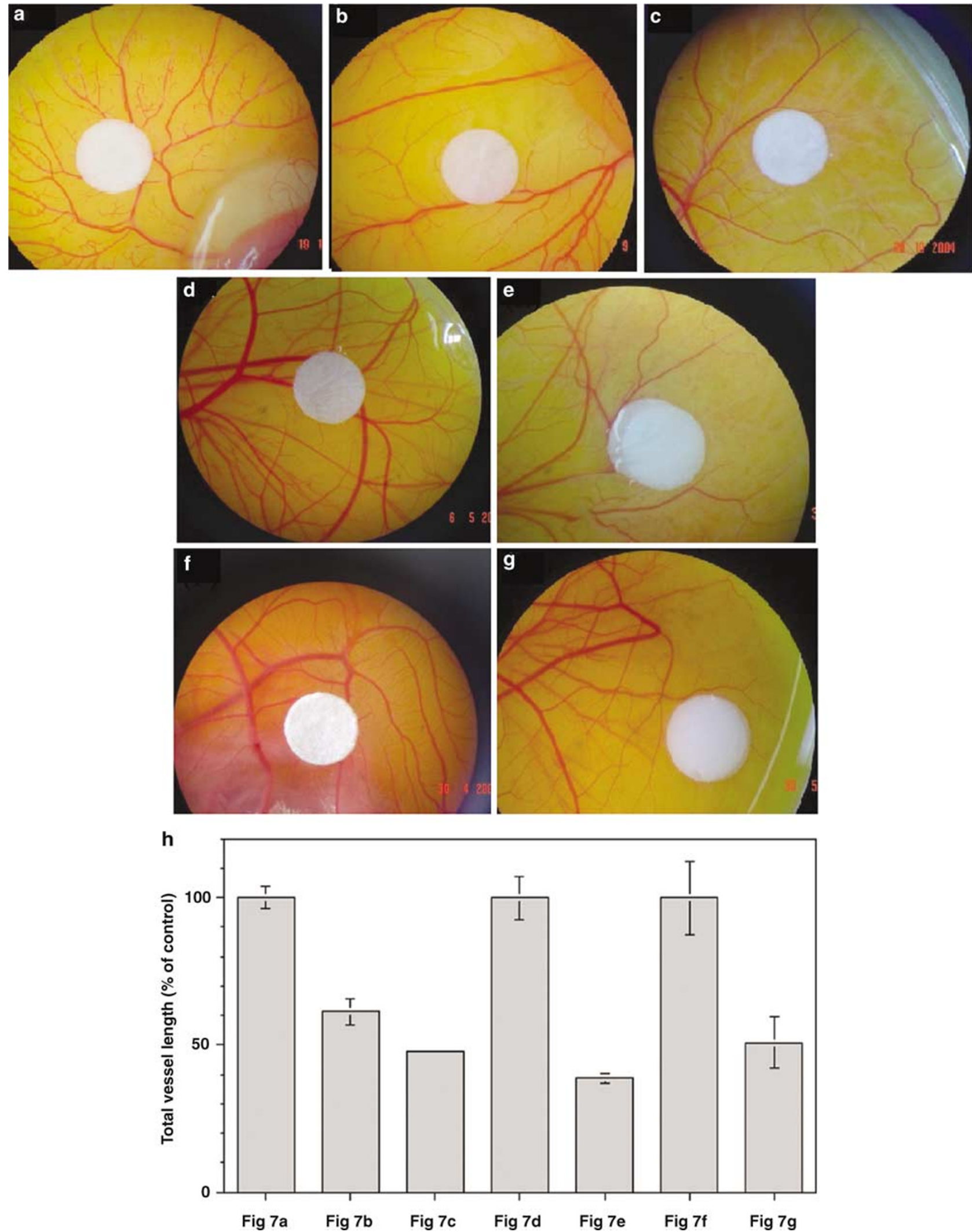

Figure 7 Effect of lebestatin on angiogenesis in CAM assay. The CAM models were prepared using 8-day-old chick embryos treated as described in Materials and methods. Filter disks were soaked in (a) $0.9 \% \mathrm{NaCl}$ alone; (b) $0.1 \mu \mathrm{g}$ of lebestatin and (c) $0.5 \mu \mathrm{g}$ of lebestatin; (d) $0.9 \% \mathrm{NaCl}$ and $10 \mathrm{ng}$ PDGF; (e) $10 \mathrm{ng}$ PDGF and $0.5 \mu \mathrm{g}$ lebestatin; (f) $200 \mathrm{ng}$ VEGF; (g) $200 \mathrm{ng}$ VEGF and $0.5 \mu \mathrm{g}$ lebestatin. After incubation for $72 \mathrm{~h}$, CAMs were photographed with a digital camera. Each group contained five CAMs and the experiment was repeated three times. (h) Quantification of the total blood vessels length was performed in a circle representing $50 \%$ of the total CAM surface. 
target for venom peptides. Obtustatin and viperistatin thus selectively inhibit binding of $\alpha 1 \beta 1$ integrin to immobilized collagen. ${ }^{11,17}$ In the present study, we show that lebestatin is also a selective $\alpha 1 \beta 1$ integrin inhibitor.

Lebestatin differs from obtustatin at position 24 (Arg/Leu) and 38 (Ser/Leu). Also, it differs from viperistatin at position 38 (Ser/Val) and 40 (Pro/ Gln). It is now well known that the KTS loop and C-terminal sequence are responsible for the activity of these peptides. Thus, amino-acid substitutions in these regions may have an effect on their biological activities. This is clearly the case as we observed that non conserved amino-acid residues are critical for the efficiency of the peptides. For example, efficiency of obtustatin to inhibit cell adhesion (IC50 $=1.8 \mathrm{nM}$ ) was improved by about 10 -fold by replacement of $\mathrm{Leu}^{24}$ (present in obtustatin) by $\mathrm{Arg}^{24}$ (present in lebestatin), leading to an IC50 of $0.22 \mathrm{nM}$, a value very similar to that of lebestatin (IC50 = $0.20 \mathrm{nM}$ ). This structure/function relationship study will be described in detail elsewhere (O Ziri, manuscript in preparation). Our results are also supported by the fact that the additional substitution present in viperistatin increased its efficiency even further. ${ }^{17}$

In addition to its effect on cell adhesion, low concentrations of lebestatin readily inhibited cell migration on collagen, by blocking $\alpha 1 \beta 1$ integrin. Lebestatin also inhibited endothelial integrins, as both adhesion and migration of HMEC-1 to type IV collagen were affected by the peptide. However, in the case of endothelial cells, the inhibitory effect was only partial, most probably due to the presence of other integrins that rescue $\alpha 1 \beta 1$.

Several models have been used to study the role of cell adhesion molecules in angiogenesis, including Matrigel tube formation, chick CAM assay, and murine Matrigel plug. ${ }^{36}$ Here we used the CAM model and found that lebestatin inhibited the spontaneous angiogenesis in a dose-dependent manner. Our data show that lebestatin is able to inhibit new vessel formation at only $0.1 \mu \mathrm{g} /$ embryo. Crosstalk between integrins and growth factor receptors is critical in all steps of angiogenesis. It was shown that VEGF can induce activation of key integrins involved in angiogenesis, ${ }^{7}$ including $\alpha 1 \beta 1$ and $\alpha 2 \beta 1$. In addition, various growth factors, including PDGF-BB have been shown to induce VEGF expression in several malignant and nonmalignant cell lines. ${ }^{37}$ VEGF shares structural homology with the PDGF family. ${ }^{38}$ In this work, we demonstrated that lebestatin treatment $(0.5 \mu \mathrm{g} /$ embryo) abruptly stopped VEGF- and PDGF-induced capillary development. Obtustatin, at $5 \mu \mathrm{g} /$ embryo, also inhibited angiogenesis induced by fibroblast growth factor 2 (FGF2) when assayed in the CAM model, ${ }^{11}$ although it seems that obtustatin is at least 10 times less active than lebestatin. This is in agreement with observed differences of the potencies of these two proteins in cell adhesion. It will be very interesting to obtain the same results for viperistatin in order to improve our knowledge of the structure-activity relationship of this peptide group.

The superimposition of the structural models of lebestatin and viperistatin with the 3D structure of obtustatin ${ }^{39}$ shows that they share similar conformational features (Figure 8a). The main structural differences between the three peptides are located in the loop that contains the KTSRTS (lebestatin and viperistatin) or KTSLTS (obtustatin) motif, and the C-terminal domain (PSYPG ${ }^{41}-\mathrm{COOH}, \mathrm{PVYQG}^{41}$ $\mathrm{COOH}$ and $\mathrm{PLYPG}^{41}$-COOH for lebestatin, viperistatin and obtustatin, respectively). It is worth noting that the KTS loop and the C-terminal domain are in close spatial proximity and located on the same side of the molecule. ${ }^{40}$ It is therefore likely that both

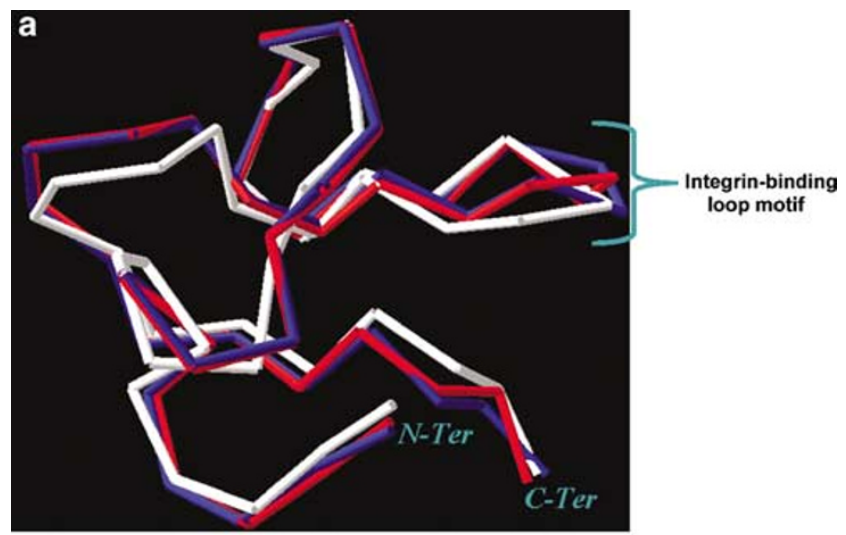

b

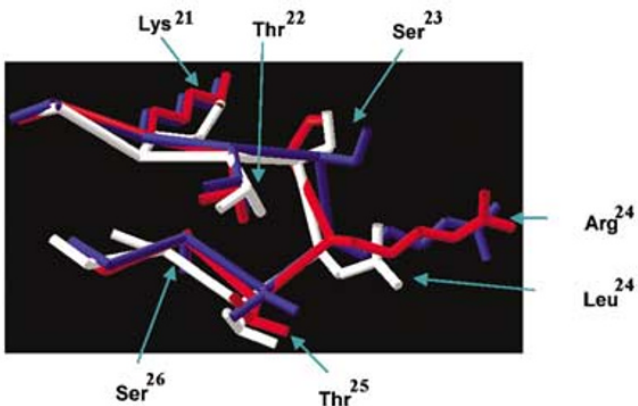

C

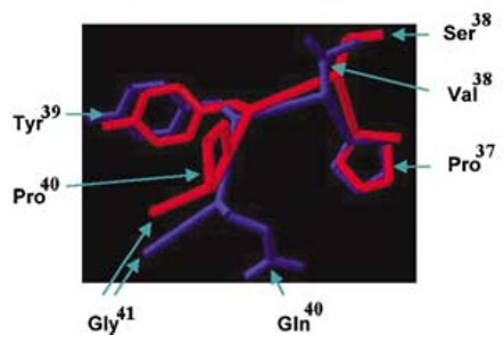

Figure 8 Molecular models of lebestatin, viperistatin and obtustatin. (a) Superimposition of backbone atoms of obtustatin (white), lebestatin (red), and viperistatin (blue). (b) Superimposition of the integrin-binding loop. The side chain of KTSRTS (lebestatin and viperistatin) and KTSLTS (obtustatin) are shown. The color code is the same as in Figure 8a. (c) Superimposition of the C-terminal region of lebestatin and viperistatin. The color code is the same as in Figure 8a. 
domains are functionally important and could be responsible for the different potencies of the compounds. Interestingly, replacement of uncharged $\mathrm{Leu}^{24}$ residue (present in less active obtustatin) by positively charged $\mathrm{Arg}^{24}$ residue (present in more active lebestatin and viperistatin) might thus play a key role for integrin interaction and antiangiogenic properties of the peptides (Figure 8b). Additionally, in the C-terminal region, replacement of $\mathrm{Val}^{38}$ (viperistatin) by $\operatorname{Ser}^{38}$ (lebestatin), and/or $\mathrm{Gln}^{40}$ (viperistatin) by $\mathrm{Pro}^{40}$ (lebestatin) are potentially important (Figure 8c).

Work is in progress in our laboratory to synthesize lebestatin analogues in order to better understand structure-activity relationships of these proteins and to define the minimum structures of $\alpha 1 \beta 1$ receptor.

\section{Acknowledgements}

We thank Professor Koussay Dellagi (Institut Pasteur de Tunis) for his continuous interest in this study and for his support. Dr Benlasfar Zakaria (Laboratoire Vétérinaire, Institut Pasteur de Tunis) and Eddy Pasquier are acknowledged for providing viper venom and HMEC-1 cells, respectively. We thank Dr Ghram Abdel Jelil (Institut Pasteur de Tunis) for use of his laboratory. We thank Professor Doug Maxwell and Martha Maxwell (Department of Plant Pathology, University of Wisconsin-Madison, USA) for critical reading of the manuscript. We thank Dr Juan J Calvete (Instituto de Biomedicina de Valencia) for his interest to this study and for his critical comments.

This work was supported in part by a grant from the CMCU (Comité Mixte de Coopération Universitaire France-Tunisie), the ARC (Association pour la Recherche sur le Cancer) and the Ligue Nationale contre le Cancer.

\section{References}

1 Dennis MS, Henzel WJ, Pitti RM, et al. Platelet glycoprotein IIb-IIIa protein antagonists from snake venoms: evidence for a family of platelet-aggregation inhibitors. Proc Natl Acad Sci USA 1990;87:24712475.

2 McLane MA, Marcinkiewicz C, Vijay-Kumar S, et al. Viper venom disintegrins and related molecules. Proc Soc Exp Biol Med 1998;219:109-119.

3 Calvete JJ, Moreno-Murciano MP, Theakston RD, et al. Snake venom disintegrins: novel dimeric disintegrins and structural diversification by disulphide bond engineering. Biochem J 2003;372:725-734.

4 Hynes RO. Integrins: bidirectional, allosteric signaling machines. Cell 2002;110:673-687.

5 Humphries MJ. Integrin structure. Biochem Soc Trans 2000;28:311-339.

6 Guo W, Giancotti FG. Integrin signalling during tumour progression. Nat Rev Mol Cell Biol 2004;5: 816-826.
7 Senger DR, Perruzzi CA, Streit M, et al. The alpha(1)beta(1) and alpha(2)beta(1) integrins provide critical support for vascular endothelial growth factor signaling, endothelial cell migration, and tumor angiogenesis. Am J Pathol 2002;160:195-204.

8 Sheu JR, Yen MH, Kan YC, et al. Inhibition of angiogenesis in vitro and in vivo: comparison of the relative activities of triflavin, an Arg-Gly-Aspcontaining peptide and anti-alpha(v)beta3 integrin monoclonal antibody. Biochim Biophys Acta 1997; 1336:445-454.

9 Yeh CH, Peng HC, Huang TF. Accutin, a new disintegrin, inhibits angiogenesis in vitro and in vivo by acting as integrin alphavbeta3 antagonist and inducing apoptosis. Blood 1998;92:3268-3276.

10 Kang IC, Lee YD, Kim DS. A novel disintegrin salmosin inhibits tumor angiogenesis. Cancer Res 1999;59:37543760.

11 Marcinkiewicz C, Weinreb $\mathrm{PH}$, Calvete JJ, et al. Obtustatin: a potent selective inhibitor of alpha1beta1 integrin in vitro and angiogenesis in vivo. Cancer Res 2003;63:2020-2023.

12 Thibault G. Sodium dodecyl sulfate-stable complexes of echistatin and RGD-dependent integrins: a novel approach to study integrins. Mol Pharmacol 2000;58: 1137-1145.

13 Scarborough RM, Rose JW, Hsu MA, et al. Barbourin. A GPIIb-IIIa-specific integrin antagonist from the venom of Sistrurus m. barbouri. J Biol Chem 1991;266:93599362.

14 Hite LA, Jia LG, Bjarnason JB, et al. cDNA sequences for four snake venom metalloproteinases: structure, classification, and their relationship to mammalian reproductive proteins. Arch Biochem Biophys 1994; 308:182-191.

15 Calvete JJ, Fox JW, Agelan A, et al. The presence of the WGD motif in CC8 heterodimeric disintegrin increases its inhibitory effect on alphaII(b)beta3, alpha(v)beta3, and alpha5beta1 integrins. Biochemistry 2002;41:20142021.

16 Moreno-Murciano MP, Monleon D, Calvete JJ, et al. Amino acid sequence and homology modeling of obtustatin, a novel non-RGD-containing short disintegrin isolated from the venom of Vipera lebetina obtusa. Protein Sci 2003;12:366-371.

17 Kisiel DG, Calvete JJ, Katzhendler J, et al. Structural determinants of the selectivity of KTS-disintegrins for the $\alpha 1 \beta 1$ integrin. FEBS Lett 2004;577:478-482.

18 Yatohgo $\mathrm{T}$, Izumi $\mathrm{M}$, Kashiwagi $\mathrm{H}$, et al. Novel purification of vitronectin from human plasma by heparin affinity chromatography. Cell Struct Funct 1988;13:281-292.

19 Sarray S, Srairi N, Hatmi M, et al. Lebecetin, a potent antiplatelet C-type lectin from Macrovipera lebetina venom. Biochim Biophys Acta 2003;1651:30-40.

20 Sarray S, Berthet V, Calvete JJ, et al. Lebectin, a novel C-type lectin from Macrovipera lebetina venom, inhibits integrin-mediated adhesion, migration and invasion of human tumour cells. Lab Invest 2004;84: 573-581.

21 Gill SC, von Hippel PH. Calculation of protein extinction coefficients from amino acid sequence data. Anal Biochem 1989;182:319-326.

22 Pasquier E, Honoré S, Pourroy B, et al. Antiangiogenic concentrations of paclitaxel induce an increase in microtubule dynamics in endothelial cells but not in cancer cells. Cancer Res 2005;65:2433-2440. 
23 Rigot V, Lehmann M, André F, et al. Integrin ligation and PKC activation are required for migration of colon carcinoma cells. J Cell Sci 1998;111:3119-3127.

24 Kadi A, Pichard V, Lehmann M, et al. Effect of microtubule disruption on cell adhesion and spreading. Biochem Biophys Res Comm 1998;246:690-695.

25 Sali A, Blundell TL. Comparative protein modelling by satisfaction of spatial restraints. J Mol Biol 1993;234: 779-815.

26 Morris AL, MacArthur MW, Hutchinson EG, et al. Stereochemical quality of protein structure coordinates. Proteins 1992;12:345-364.

27 Barbouche R, Marrakchi N, Mansuelle P, et al. Novel anti-platelet aggregation polypeptides from Vipera lebetina venom: isolation and characterization. FEBS Lett 1996;39:6-10.

28 Marrakchi N, Mabrouk K, Regaya I, et al. Lebetin peptides: potent platelet aggregation inhibitors. Haemostasis 2001;31:207-210.

29 Gan ZR, Gould RJ, Jacobs JW, et al. Echistatin. A potent platelet aggregation inhibitor from the venom of the viper, Echis carinatus. J Biol Chem 1988;263:1982719832.

30 Dennis MS, Henzel WJ, Pitti RM, et al. Platelet glycoprotein IIb-IIIa protein antagonists from snake venoms: evidence for a family of platelet-aggregation inhibitors. Proc Natl Acad Sci USA 1990;87:24712475.

31 Calvete JJ, Wang Y, Mann K, et al. The disulfide bridge pattern of snake venom disintegrins, flavoridin and echistatin. FEBS Lett 1992;309:316-320.

32 Golubkov V, Hawes D, Markland FS. Anti-angiogenic activity of contortrostatin, a disintegrin from Agkis- trodon contortrix contortrix snake venom. Angiogenesis 2003;6:213-224.

33 Yeh CH, Peng HC, Yang RS, et al. Rhodostomin, a snake venom disintegrin, inhibits angiogenesis elicited by basic fibroblast growth factor and suppresses tumor growth by a selective alpha(v)beta(3) blockade of endothelial cells. Mol Pharmacol 2001;59: 1333-1342.

34 Ruegg C, Dormond O, Mariotti A. Endothelial cell integrins and COX-2: mediators and therapeutic targets of tumor angiogenesis. Biochim Biophys Acta 2004; 1654:51-67.

35 Colorado PC, Torre A, Kamphaus G, et al. Antiangiogenic cues from vascular basement membrane collagen. Cancer Res 2000;60:2520-2526.

36 Stromblad S, Cheresh DA. Cell adhesion and angiogenesis. Trends Cell Biol 1996;6:462-468.

37 Stavri GT, Hong Y, Zachary IC, et al. Hypoxia and platelet-derived growth factor-BB synergistically upregulate the expression of vascular endothelial growth factor in vascular smooth muscle cells. FEBS Lett 1995;358:311-315.

38 Conn G, Bayne ML, Soderman DD, et al. Amino acid and cDNA sequences of a vascular endothelial cell mitogen that is homologous to platelet-derived growth factor. Proc Natl Acad Sci USA 1990;87:2628-2632.

39 Paz Moreno-Murciano M, Monleon D, Marcinkiewicz $\mathrm{C}$, et al. NMR solution structure of the non-RGD disintegrin obtustatin. J Mol Biol 2003;329:135-145.

40 Monleon D, Moreno-Murciano MP, Kovacs H, et al. Concerted motions of the integrin-binding loop and the C-terminal tail of the non-RGD disintegrin obtustatin. J Biol Chem 2003;278:45570-45576. 